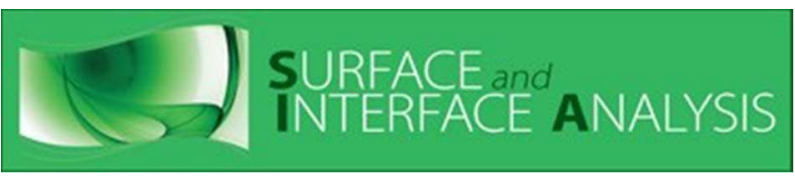

\title{
Determination of surface $\zeta$-potential and isoelectric point of carbon surfaces using tracer particle suspensions
}

\begin{tabular}{|r|l|}
\hline Journal: & Surface and Interface Analysis \\
\hline Manuscript ID & SIA-16-0176.R1 \\
\hline Wiley - Manuscript type: & Research Article \\
\hline Date Submitted by the Author: & n/a \\
\hline Complete List of Authors: & $\begin{array}{l}\text { Vasconcelos, Joana; University of Dublin Trinity College, Chemistry } \\
\text { Zen, Federico; University of Dublin Trinity College, Chemistry } \\
\text { Stamatin, Serban; University of Dublin Trinity College, Chemistry; Ustav } \\
\text { fyzikalni chemie J Heyrovskeho Akademie Ved Ceske Republiky, Physical } \\
\text { Chemistry } \\
\text { Behan, James; University of Dublin Trinity College, Chemistry } \\
\text { Colavita, Paula; University of Dublin Trinity College, Chemistry; Centre for } \\
\text { Research on Adaptive Nanostructures and Nanodevices (CRANN), }\end{array}$ \\
\hline Keywords: & \begin{tabular}{l} 
zeta potential, electrophoresis, electroosmosis, tracer, carbon \\
\hline
\end{tabular} \\
\hline
\end{tabular}




\title{
Determination of surface $\zeta$-potential and isoelectric point of
}

\section{carbon surfaces using tracer particle suspensions}

\author{
Joana M. Vasconcelos, Federico Zen, Serban N. Stamatin, James A. Behan, Paula E. Colavita* \\ School of Chemistry, Centre for Research on Adaptive Nanostructures and Nanodevices \\ (CRANN) and AMBER Research Centre, Trinity College Dublin, College Green, Dublin 2, \\ Ireland.
}

\section{Corresponding Author \\ *Email: colavitp@tcd.ie}

\begin{abstract}
Present Addresses
$\dagger$ Present address: J. Heyrovsky Institute of Physical Chemistry of the CAS, Prague, Czech Republic.
\end{abstract}




\begin{abstract}
Carbon materials are widely used in a range of applications from biomaterials to sensing and electronics. Many of these applications rely on the ability to control carbon/water interfacial properties, in particular surface charge density. This work reports a study of the electrokinetic properties of amorphous carbon thin films as a function of $\mathrm{pH}$ and surface chemistry. Surface $\zeta$ potential (SZP) and isoelectric point were determined using the tracer particle method. Initially the use of sulfonated and amine-terminated latex bead suspensions as tracer particles for the determination of SZP of reference polymer surfaces was validated. The tracer particle method was then applied to the determination of SZP and isoelectric point of macroscopic carbon surfaces with different surface chemistry. Highly graphitic and $\mathrm{sp}^{3}$-rich hydrogenated carbon surfaces were found to display negative SZP, as expected for hydrophobic surfaces. The isoelectric point of the most highly graphitic surface was found to be $\mathrm{pH}_{\mathrm{iso}}=3.7$. Surface oxidation of these films resulted in a decrease of SZP at all $\mathrm{pH}$ values and in a downshift of $\mathrm{pH}_{\text {iso }}$ to values lower than 1.5 , consistently with the presence of surface acidic groups arising from oxidation. Results indicate that the specific choice of acid/base chemistry for the tracer particles does not significantly affect either $\mathrm{SZP}$ or $\mathrm{pH}_{\mathrm{iso}}$ determinations. These results show that the tracer particle method in combination with widely available latex beads as tracers can be applied for the determination of carbon SZP as a function of $\mathrm{pH}$.
\end{abstract}

Keywords: zeta potential, amorphous carbon, tracer particles, electroosmosis, electrophoresis. 


\section{Introduction}

Carbon materials display a wide range of physicochemical, optical and electronic properties. ${ }^{[1,2]}$ Nanomaterials such as nanodiamonds, ${ }^{[3,4]}$ nanotubes, ${ }^{[5]}$ graphene and C-dots ${ }^{[6]}$ are the subject of intense study for vast number of applications such as biomaterials, sensing, electronics, therapeutics, catalysis, separation technologies and mechanical reinforcements. ${ }^{[7-9]}$ Carbon in the form of coatings and thin-films has also gained great attention in the medical sector, specifically in biosensing, orthopedic and cardiovascular fields ${ }^{[10,11]}$ and in the electronics sector. ${ }^{[12-14]}$ Many of the above applications rely on careful control of interfacial properties in order to modulate chemical/electrochemical reactivity or biological response.

Surface charge is one of the key properties that can determine rate and yield of surface reactions and the strength of interactions at carbon interfaces. Surface $\zeta$-potential (SZP) measurements are a common method of monitoring the effect of chemical treatments and surface modifications on surface electrostatic charge, ${ }^{[15,16]}$ isoelectric point and, indirectly, density of surface ionizable groups (e.g. $-\mathrm{COOH},-\mathrm{NH}_{2}$ ). These measurements have a long history in the characterization of carbon nanomaterials and carbon particles, particularly due to the numerous applications of carbon particles as adsorbers and carriers. ${ }^{[17-19]}$ SZP measurements on particles or colloids rely on determinations of particle electrophoretic mobility in liquid suspensions and several instrumentation platforms are currently available to carry out these determinations. SZP measurements on macroscopic surfaces, on the other hand, usually require specialized equipment that is not widely available. The preferred methods for macroscopic surfaces are based on determinations of streaming potential or electro osmotic mobility using microchannels that are coated with the surface under investigation. In the first case, a pressure-driven flow through the micro channel leads to the establishment of a streaming potential that is proportional to surface $\zeta$ - 
potential. $^{[20]}$ In the second case, an electric field is used to create an electro osmotic flow in a coated microchannel, and the electro osmotic mobility is then related to surface $\zeta$-potential. Kirby and Hasselbrink ${ }^{[21]}$ have previously reviewed this family of electrokinetic methods with particular emphasis on polymeric materials for microfluidics. However, to the best of our knowledge, there are only few reports of the use of these techniques on amorphous carbon coatings in the scientific literature. ${ }^{[17,22-24]}$

An alternative to measurements on coated microchannels consists of measuring the mobility of tracer particles of known $\zeta$-potential in close proximity of the surface that is the object of characterization. Tracer particle methods were used by Yan et al. ${ }^{[25]}$ in order to measure surface and particle $\zeta$-potential simultaneously. Recently, Corbett et al. ${ }^{[26-28]}$ developed a protocol based on tracer particles to determine the $\zeta$-potential of macroscopic solid surfaces, which is briefly described in the experimental section. This method is advantageous as it allows for the measurement of $\zeta$-potential of a macroscopic surface on the same instrumentation platform used to measure $\zeta$-potential of particles and bypasses many of the challenges of microchannel measurements. However, despite its potential as a rapid and cost effective approach to $\zeta$-potential determinations, there are few protocols that establish criteria for tracer particle selection and preparation. More specifically, there are no published protocols for the selection and preparation of tracer particles for $\mathrm{pH}$-dependent measurements of SZP, which are necessary for the determination of surface isoelectric points. Finally, there is no information on whether particle surface chemistry influences measured values; this is important for surfaces such as carbon which can display a wide range of chemical functionalities and/or chemisorption sites.

In this work, a protocol for the application of the tracer particle method to the determination of SZP and isoelectric point of carbon surfaces as a function of $\mathrm{pH}$ is reported. The use of 
sulfonated (SL) and amine-terminated (AL) latex bead as tracer particles was investigated. These particles possess colloidal stability over a wide $\mathrm{pH}$ range and are commercially available to all researchers interested in carrying out $\zeta$-potential measurements with this method. Initially the use of these particle suspensions was validated using standard polymeric surfaces and then application to the determination of SZP and isoelectric point of macroscopic carbon surfaces was demonstrated. The method was found to be sensitive to chemical changes at the carbon surface and was effective at establishing isoelectric points, an important requirement for understanding the behaviour of macroscopic carbon surfaces in aqueous media.

\section{Experimental Methods}

Chemicals and Materials. Hydrochloric acid (37\%), sodium hydroxide, isopropyl alcohol, sulfuric acid (95-97\%), hydrogen peroxide (30\%), methanol (semiconductor grade) and phosphate buffer saline (PBS) were purchased from Sigma Aldrich; all were used without further purification. Millipore water (> $18 \mathrm{M} \Omega$ ) was used for all experiments. Si wafers (MicroChemicals), polyester transparency films (3M), Nylon 6,6 sheets (Goodfellow) and polytetrafluoroethylene (PTFE) sheets were sonicated in isopropyl alcohol for 10 min prior to further use as substrate materials. Standard $\varnothing 300 \mathrm{~nm}$ latex tracer particles suspensions, $1 \mathrm{mM}$ $\mathrm{NaCl}, \mathrm{pH} 9.2$ were purchased from Malvern (DTS1235). Sulfate latex beads $(8 \% \mathrm{w} / \mathrm{v}, \varnothing 0.5 \mu \mathrm{m})$ and aliphatic amine latex beads $(2 \% \mathrm{w} / \mathrm{v}, \varnothing 0.4 \mu \mathrm{m})$ were purchased from Life Technologies.

Preparation of tracer particle suspensions. Suspensions of sulfonated latex beads $\left(50 \times 10^{-6}\right.$ $\mathrm{v} / \mathrm{v})$ and amine-terminated latex beads $\left(50 \times 10^{-6} \mathrm{v} / \mathrm{v}\right)$ were prepared in $100 \mu \mathrm{M}$ PBS solution containing $1.37 \mathrm{mM} \mathrm{NaCl}$ and $27 \mu \mathrm{M} \mathrm{KCl}$. A range of solutions with $\mathrm{pH} 4.5-8.5$ were prepared for studies of $\zeta$-potential as a function of $\mathrm{pH} ; \mathrm{HCl}$ and $\mathrm{NaOH}$ were used to adjust the $\mathrm{pH}$ of the 
PBS buffer to the desired value. The ionic strength remained at $1.80 \pm 0.15 \mathrm{mM}$ for all studies where $\mathrm{pH}$ was monitored.

Surface preparation. A DC-magnetron sputtering chamber (Torr International, Inc.) was used to deposit amorphous carbon (a-C) films at a base pressure of $\leq 2 \times 10^{-6}$ mbar and a deposition Ar pressure of $7 \times 10^{-3}$ mbar, as previously described. ${ }^{[29]}$ Hydrogenated amorphous carbon (a$\mathrm{C}: \mathrm{H})$ films were prepared using a $\mathrm{H}_{2} / \mathrm{Ar}$ gas mixture $\left(10 \% \mathrm{H}_{2}, 90 \% \mathrm{Ar}\right)$ as previously described. Oxidized amorphous carbon (a-C:O) was prepared by oxidation of a-C surfaces under a UV lamp for $2 \mathrm{~h}$ in air, a well established oxidation method for carbon coatings and nanomaterials. ${ }^{[30,31]}$

Characterization Methods. X-ray photoelectron spectroscopy (XPS) characterization was performed using an Omicron ultrahigh vacuum system $\left(1 \times 10^{-10}\right.$ mbar base pressure $)$ equipped with a monochromated $\mathrm{Al} \mathrm{K \alpha}$ source $(1486.6 \mathrm{eV})$ and a multichannel array detector. Spectra were recorded at $45^{\circ}$ take-off angle. Peaks were fitted to Voigt functions after Shirley background correction using Casa XPS software; atomic ratios were obtained from area ratios using relative sensitivity factors $(\mathrm{C}=1.00 ; \mathrm{O}=2.93)$. Atomic force microscopy (AFM, Asylum Research) imaging was performed in tapping mode (1 Hz and 512 scan lines) using Au-coated silicon cantilevers with nominal spring constant in the range $1.45-15.1 \mathrm{~N} \mathrm{~m}^{-1}$ (NT-MDT). Spectroscopic ellipsometry (SE) measurements of amorphous carbon surfaces were performed using a J.A. Woolam Co. Inc. alpha-SETM ellipsometer; data were modelled using CompleteEASE ${ }^{\mathrm{TM}}$ software as discussed in the Supporting Information. ${ }^{[32]}$ Dynamic light scattering (DLS) and $\zeta$-potential measurements were carried out using a Malvern Zetasizer Nano-ZS, $\lambda=633 \mathrm{~nm}$ He-Ne laser; the signal was detected at $173^{\circ}$ and $13^{\circ}$ for DLS and $\zeta$ potential measurements, respectively. Hydrodynamic size was determined using a refractive index $\mathrm{n}=1.59$ for latex. ${ }^{[33]}$ Particle $\zeta$-potential was obtained using the same instrument which 
determines particle velocity and mobility via phase analysis light scattering (PALS); ${ }^{[26]}$ solution conditions were optimized as described below.

Tracer particle suspensions and determinations of SZP. The tracer particle method for measuring the SZP of a static macroscopic surface requires the use of a suspension of narrowly dispersed particles with well-defined SZP. This method has been previously described by Corbett et $a l . ;^{[26]}$ briefly, the velocity of the tracer particles under the effect of an AC field is measured via phase analysis light scattering after positioning the surface under characterization at progressively greater distances from the probed volume. The velocity of the tracer particles at each position is the result of the sum of the particle electrophoretic migration, and of the electro osmotic flow in the proximity of the solid/liquid interface. As the probing volume is positioned further away from the surface the effect of electro osmotic flow decreases until the observed mobility becomes only the result of electrophoretic migration. The apparent $\zeta$-potential is calculated from each mobility measurement using equation $\zeta=\mu_{e o} \eta / \varepsilon$, where $\mu_{e o}$ is the electroosmotic mobility, $\varepsilon$ is the permittivity and $\eta$ is the solution viscosity. ${ }^{[26]}$ Values obtained are plotted vs. surface displacement and the SZP is obtained from extrapolation to zerodisplacement; the contribution arising exclusively from the surface $\left(\zeta_{\text {surface }}\right)$ is calculated from the intercept as in equation (1):

$$
\zeta_{\text {surface }}=- \text { intercept }+\zeta_{\text {particle }}
$$

An example of this procedure is shown in Figure 2.

Surface $\zeta$-potential measurements were performed using a surface $\zeta$-potential cell (Malvern Instruments). Mobility determinations were conducted at 125, 250, 375, 500 and $1000 \mu \mathrm{m}$ 
displacements from the sample surface. Thin film samples were prepared with the dimensions of $4 \times 4 \mathrm{~mm}$ to fit the cell sample holder. SL and AL beads were used as tracer particles in suspensions containing $100 \mu \mathrm{M}$ PBS buffer $(1.37 \mathrm{mM} \mathrm{NaCl}$ and $27 \mu \mathrm{M} \mathrm{KCl})$ of total ionic strength $1.80 \pm 0.15 \mathrm{mM}$ at all $\mathrm{pH}$ values studied. A buffered suspension at $\mathrm{pH}=7.4$ was prepared first and $\mathrm{pH}$ was varied via addition of $\mathrm{HCl}$ or $\mathrm{NaOH}$ as appropriate; the error bar for the ionic strength reflects the range of variation introduced by the $\mathrm{pH}$ adjustment process. The conductivity of the suspension was optimized for values in the range 200-300 $\mu \mathrm{S} / \mathrm{cm}$; values above this range were found to lead to electrochemical degradation of cell electrodes or of the beads, and were found to result in large deviations in calculated SZPs. Error bars indicate standard deviations calculated from three measurements on each sample.

\section{Results}

Characterization of particle suspensions. The tracer particle method was used to investigate the surface $\zeta$-potential of thin films as a function of $\mathrm{pH}$. Two different tracer particle suspensions were used for this purpose, sulfate latex (SL) and aliphatic amine latex (AL) beads, which are terminated with $-\mathrm{SO}_{3} \mathrm{H}$ and $-\mathrm{NH}_{2}$ groups, respectively.

Figure 1a shows the hydrodynamic size of SL and AL beads as a function of $\mathrm{pH}$, obtained from DLS measurements. The hydrodynamic size of SL beads remains constant as a function of $\mathrm{pH}$ and the average value was found to be $582 \pm 3 \mathrm{~nm}$, indicating that the average hydrodynamic size is only marginally higher than the nominal diameter under the experimental conditions. AL beads also exhibit an approximately constant hydrodynamic diameter with average value of 553 $\pm 11 \mathrm{~nm}$. These results indicate that both SL and AL bead suspensions are stable and do not aggregate or sediment over the $\mathrm{pH}$ range of 4.5-8.5. 

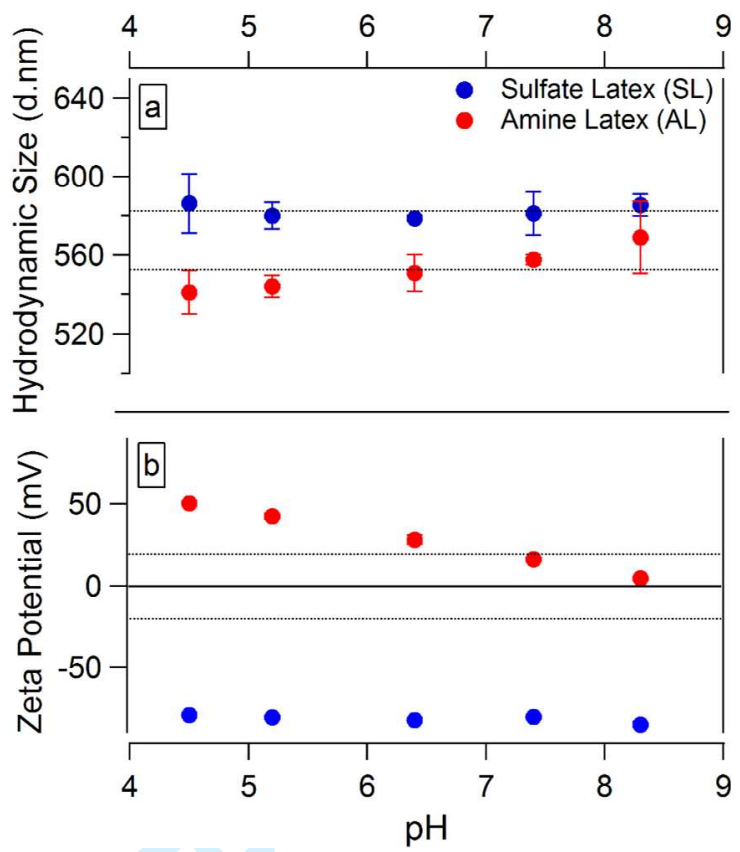

Figure 1. (a) Hydrodynamic size and (b) $\zeta$-potential of sulfate latex (SL) and amine latex (AL) beads used as tracer particles for surface $\zeta$-potential measurements. SL and AL beads were suspended in $100 \mu \mathrm{M}$ PBS buffer $(1.37 \mathrm{mM} \mathrm{NaCl}$ and $27 \mu \mathrm{M} \mathrm{KCl})$ with total ionic strength of $1.80 \pm 0.15 \mathrm{mM}$ for all $\mathrm{pH}$ values studied.

Figure $1 \mathrm{~b}$ shows the SZP of SL and AL particles as a function of $\mathrm{pH}$, at a constant total ionic strength of $1.80 \mathrm{mM}$. The $\zeta$-potential of SL beads remains at approximately $-80 \mathrm{mV}$ at all $\mathrm{pH}$ values, which is consistent with the presence of $-\mathrm{SO}_{3} \mathrm{H}$ groups at the particle surface that are acidic with $\mathrm{pK}_{\mathrm{a}}<2$. The results for SL particles are in agreement with those reported by Thielbeer et $a l .{ }^{[34]}$ who compared the $\zeta$-potential of microparticles with different surface functional groups. AL beads display positive $\zeta$-potential values, which range from a maximum value of $50.5 \pm 1.0 \mathrm{mV}$ at $\mathrm{pH} 4.5$ to approximately $5 \mathrm{mV}$ at $\mathrm{pH} 8.3$; a linear extrapolation of the results to the $\mathrm{pH}$-axis yields an estimate of $\mathrm{pH}_{\mathrm{iso}}$ of 8.8 . Cros et al. showed $\zeta$-potential measurements of aminated $\left(-\mathrm{NH}_{2}\right)$ latex particles $(10 \mathrm{mM} \mathrm{NaCl})$ as a function of $\mathrm{pH}$, and found 


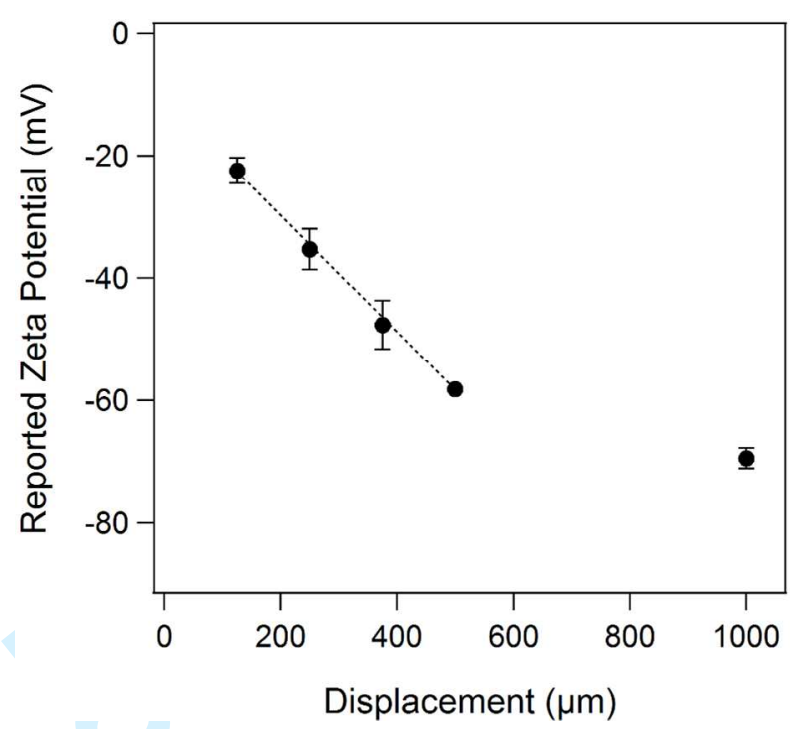

Figure 2. Plot of apparent $\zeta$-potential as a function of surface displacement obtained for Nylon $6,6$ as a static surface using SL beads in $100 \mu \mathrm{M}$ PBS buffer ( $\mathrm{pH} 7.5)$ as tracer particles.

that for acidic $\mathrm{pH}$ the particles show a stable $\zeta$-potential of $60 \mathrm{mV}$ that decreases to $0 \mathrm{mV}$ at $\mathrm{pH} \sim$ 9. ${ }^{[35]}$ The results presented here are in good agreement with the above study, and indicate that AL beads are stable in acidic media and that they possess an isoelectric point of 8.8 .

Characterization of Nylon and PTFE surfaces using tracer particles. To confirm that the tracer particle suspensions could be applied to SZP determinations as a function of $\mathrm{pH}$, we investigated the performance of latex bead suspensions in the determination of the SZP of two standard polymeric surfaces: Nylon 6,6 and PTFE. Figure 2 shows an example of a surface $\zeta$ potential measurement on Nylon 6,6, using SL beads as tracer particles, suspended in a $100 \mu \mathrm{M}$ PBS buffer at $\mathrm{pH}$ 7.5. The plot shows the reported $\zeta$-potential - calculated from the measured mobility of the tracer particles - as a function of surface displacement. The intercept (eq. 2) is obtained via linear extrapolation of the reported $\zeta$-potential, excluding the value obtained at 1000 $\mu \mathrm{m}$, for which the apparent $\zeta$-potential matches that in bulk suspensions. ${ }^{[26]}$ 


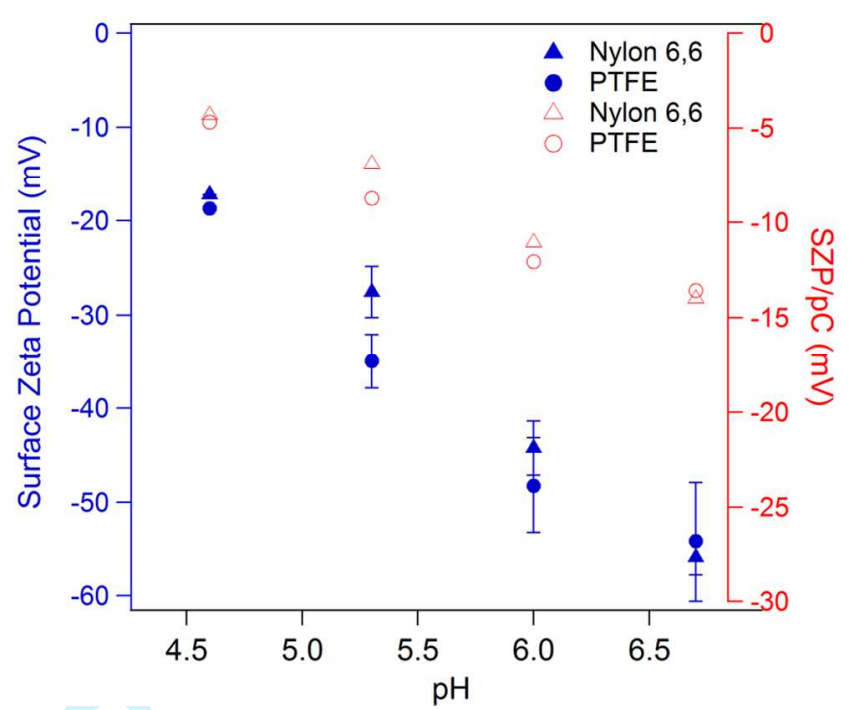

Figure 3. Surface $\zeta$-potential measurements of Nylon 6,6 and PTFE surfaces (blue data points) using SL beads as tracer particles. SL beads were suspended in $100 \mu \mathrm{M}$ PBS buffer $(1.37 \mathrm{mM}$ $\mathrm{NaCl}$ and $27 \mu \mathrm{M} \mathrm{KCl}$ ) and the ionic strength remained at $1.80 \pm 0.15 \mathrm{mM}$ for all $\mathrm{pH}$ studied (pC $=2.82$ ). Surface $\zeta$-potential values were normalized by the counterion concentration (pC) for both polymers (red data points).

Figure 3 displays the SZP ( $\zeta_{\text {surface }}$ ) of PTFE and Nylon 6,6 obtained using SL beads as tracers, over the $\mathrm{pH}$ range 4-7; SZP values normalized by counterion concentration (pC) are also reported on the right-hand axis to facilitate comparison with literature data. PTFE and Nylon 6,6 show similar SZP at all $\mathrm{pH}$ values that compare well to those reported in literature (see below): ${ }^{[21,36]}$ values were found to decrease from approximately $-20 \mathrm{mV}$ at $\mathrm{pH} 4.4$ to less than $-50 \mathrm{mV}$ for $\mathrm{pH}$ 6.7. Extrapolation to the $\mathrm{x}$-axis yielded an estimate of $\mathrm{pH}_{\mathrm{iso}}$ of 3.7 and 3.4 for Nylon and PTFE, respectively. Results obtained with SL tracer particles are similar to reports of $\zeta$-potential for Nylon and PTFE obtained via streaming potential determinations in the literature. Kirby et al. ${ }^{[21]}$ published a review of SZP determinations for common polymeric substrates using microchannel methods at various $\mathrm{pH}$ and ionic strength values, which allows for a comparison with tracer particle SZP determinations. For instance, Rendall et al. ${ }^{[36]}$ reported 


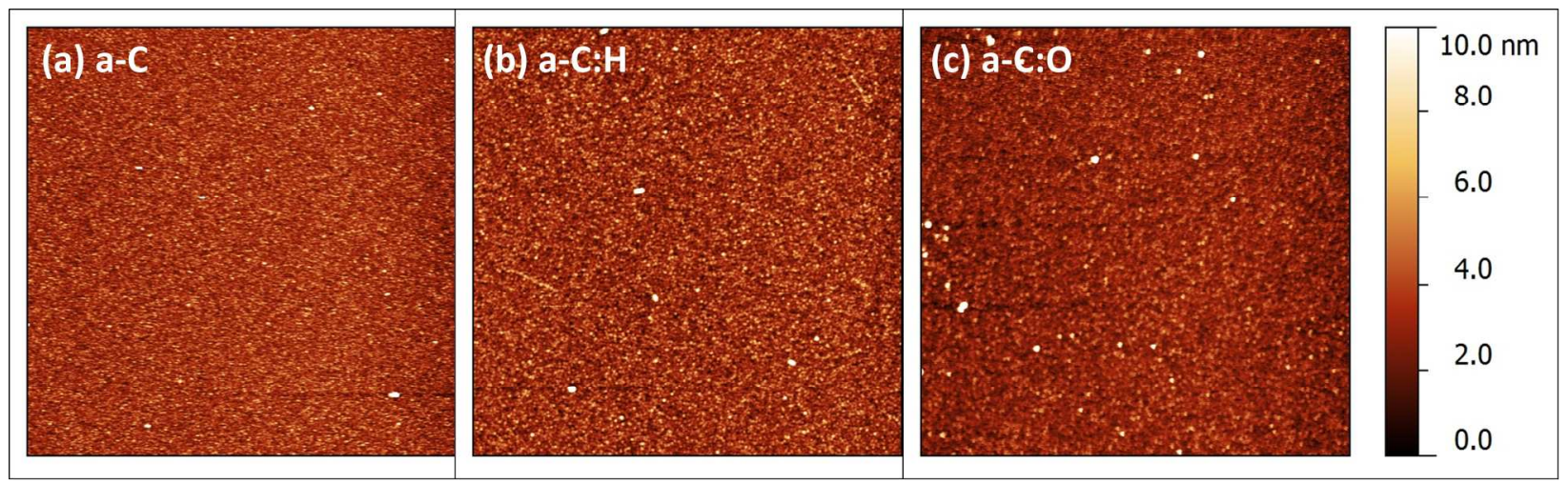

Figure 4. $10 \times 10 \mu \mathrm{m}$ AFM topographic images of (a) a-C, (b) a-C:H and (c) a-C:O surfaces. Surfaces roughness values were obtained from height profile determinations.

similar SZP for $\mathrm{pC}=2.0-4.0$ in the $\mathrm{pH}$ range of our study. Werner et al. ${ }^{[15]}$ studied the influence of $\mathrm{pC}$ on the SZP of flat solid surfaces and reported SZP/pC ratios for PTFE substrates, that are comparable to those shown in Figure 3. Therefore, the tracer particle method in combination with latex bead suspensions appears to offer a satisfactory protocol for the determination of SZP of macroscopic surfaces.

Characterization of amorphous carbon films. Many of the applications of amorphous carbon films and coatings rely on the ability to control carbon interfacial properties and, in particular, surface charge density. SZP measurements using tracer particles were performed on three different amorphous carbon surfaces, a-C, a-C:H and a-C:O, all of which were fabricated in our lab as described in the experimental section.

Amorphous carbon films used for our experiments are relatively smooth and featureless, as shown by SEM imaging (see Supporting Information). AFM measurements (Figure 4) yielded rms roughness values for a-C, a-C:H and a-C:O of $(0.94 \pm 0.03) \mathrm{nm},(1.16 \pm 0.08) \mathrm{nm}$ and $(0.86$ $\pm 0.07) \mathrm{nm}$, respectively, in good agreement with previous determinations on sputtered carbon 
films. ${ }^{[37,38]}$ The electronic properties of these films were characterized via spectroscopic ellipsometry as described in the Supporting Information. Optical constants determined from ellipsometry data for a-C and a-C:H films were used to calculate the absorption coefficient and subsequently determine the Tauc gap $\left(\mathrm{E}_{\mathrm{T}}\right)$ of the amorphous carbon. Average $\mathrm{E}_{\mathrm{T}}$ values were found to be $0.66 \pm 0.01 \mathrm{eV}$ and $1.77 \pm 0.01 \mathrm{eV}$ for a-C and a-C:H, respectively (95\% C.I.), thus confirming that a-C has a greater metallic character than a-C:H. This indicates that a-C films possess a higher graphitic content, in agreement with materials deposited using similar protocols $^{[29]}$ and with XPS results in this work (see below). a-C:O films are the result of a surface oxidation of a-C, therefore, spectroscopic ellipsometry was used to determine the thickness of the oxidized layer (see Supporting Information) which was found to be $2.8 \pm 0.2 \mathrm{~nm}$.

The surface chemistry of these three carbon materials was studied via XPS characterization. Figure 5 shows the $\mathrm{C} 1 \mathrm{~s}$ spectra of a-C, a-C:H and a-C:O surfaces; all three display a main asymmetric peak characteristic of amorphous carbon. The main $\mathrm{C} 1 \mathrm{~s}$ peak of a-C and a-C:O was satisfactorily fitted with two main contributions at $284.4 \mathrm{eV}$ and $285.1 \mathrm{eV}$ attributed to trigonally $\left(\mathrm{sp}^{2}\right)$ and tetrahedrally $\left(\mathrm{sp}^{3}\right)$ bonded carbon $(\mathrm{C}-\mathrm{C})$, respectively. Only the $\mathrm{sp}^{3}$ contribution was necessary to obtain a satisfactory fit for a-C:H surfaces, thus confirming that this surface is rich in $\mathrm{sp}^{3}$ centres. This finding is in agreement with previous work, ${ }^{[2]}$ which had shown that the introduction of hydrogen in the carbon scaffold occurs mainly via formation of $\mathrm{C}-\mathrm{H}$ bonds, as shown in greater detail in the Supporting Information. The fraction of graphitic carbon can be estimated from the $\mathrm{A}_{284} / \mathrm{A}_{285+284}$ area ratios to be $85 \%, 82 \%$ and $0 \%$ for a-C, a-C:O and a-C:H, respectively. a-C, and to a greater extent a-C:O, also show contributions at high binding energy $(286-288 \mathrm{eV})$ that arise from the presence of oxidized groups $(\mathrm{C}-\mathrm{O}, \mathrm{C}=\mathrm{O})$. In the case of a-C:O 


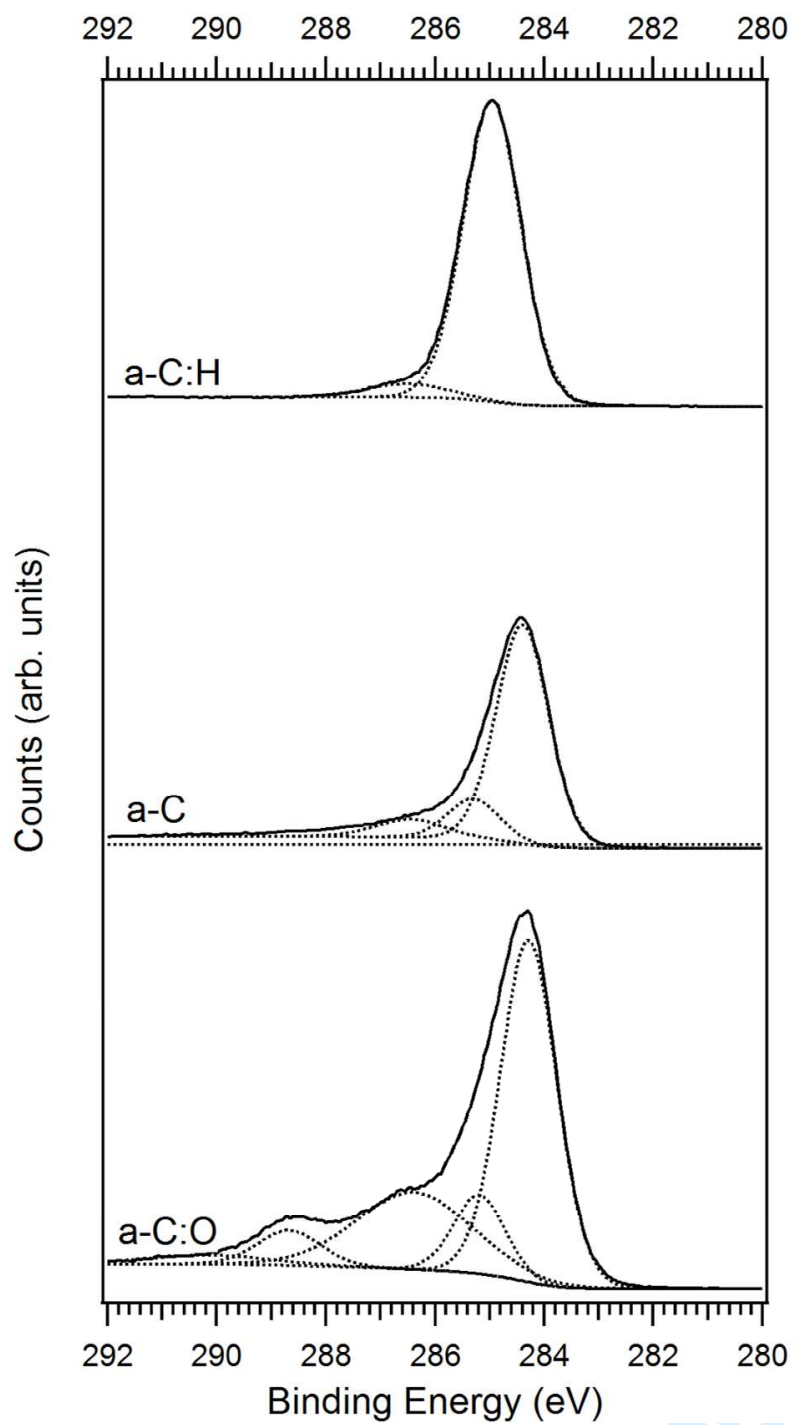

Figure 5. XPS spectra of a-C:H, a-C and a-C:O in the $\mathrm{C} 1$ s region; Shirley background and individual contributions are shown under each curve.

a contribution at $288.7 \mathrm{eV}$ indicates the presence of carboxyl groups as a result of the oxidation process. ${ }^{[39]}$ The oxygen content of the three carbon materials was obtained from fits of the $\mathrm{O} 1 \mathrm{~s}$ peak at $532 \mathrm{eV}$ (data not shown). The peak area ratio $\mathrm{A}_{\mathrm{O} 1 \mathrm{~s}} / \mathrm{A}_{\mathrm{C} 1 \mathrm{~s}}$ corrected by relative sensitivity factors yielded $\mathrm{O} / \mathrm{C}$ at $\%$ contents of $5 \%, 8 \%$ and $20 \%$ for a-C:H, a-C and a-C:O, respectively. 
The high $\mathrm{O} / \mathrm{C}$ content observed for $\mathrm{a}-\mathrm{C}: \mathrm{O}$ is consistent with the sample having undergone oxidative treatment. In summary, XPS results indicate that the three carbon surfaces chosen for our studies display significantly different properties, in particular the materials were found to have increasing graphitic content in the order $\mathrm{a}-\mathrm{C}: \mathrm{H}<\mathrm{a}-\mathrm{C}: \mathrm{O}<\mathrm{a}-\mathrm{C}$. They were also found to have increasing density of oxidized groups in the order a-C:H $<\mathrm{a}-\mathrm{C}<\mathrm{a}-\mathrm{C}: \mathrm{O}$.

Differences in carbon surface chemistry also resulted in changes in wetting behaviour. Static water contact angle (WCA) measurements were carried out on a-C, a-C:H and a-C:O surfaces yielding values of $(35.2 \pm 2.9)^{\circ}{ }^{[32]}(46.6 \pm 2.6)^{\circ}$ and $(3.2 \pm 0.4)^{\circ}$, respectively. Values obtained for a-C and a-C:H are in good agreement with previous determinations on similarly deposited carbon thin films. ${ }^{[40,41]}$ The oxidation process increases surface hydrophilicity, as expected based on the presence of oxidized groups as determined via XPS.

The SZP of the three carbon surfaces was determined via mobility determinations of tracer particles. In order to understand whether tracer particle chemistry can potentially affect the observed SZP, pH-dependent studies were carried out using both SL and AL particles, which possess ionizable groups with different acid-base chemistry. Figure 6 shows a summary of SZP values for a-C, a-C:H and a-C:O surfaces obtained with SL (blue) and AL (red) particles as a function of $\mathrm{pH}$. The most graphitic surface, a-C, displays SZP values of $-51 \pm 2 \mathrm{mV}$ and $-63 \pm 5$ $\mathrm{mV}$ at $\mathrm{pH} 7.4$ using SL and AL suspensions, respectively; the SZP value increases with decreasing $\mathrm{pH}$ to $-25 \mathrm{mV}$ at $\mathrm{pH}$ 4.4. Extrapolation to the $\mathrm{pH}$-axis yielded an estimate of $\mathrm{pH}_{\text {iso }}$ for a-C of 3.0 and 3.7 when SL and AL beads were used, respectively. In the case of a-C:H surfaces, it appears more difficult to identify a clear trend in SZP vs. $\mathrm{pH}$ and a determination of isoelectric points was not attempted. SZP values for a-C:H were found to be in general more positive than those observed for a-C under the same conditions; for instance, the SZP of a-C:H was found to 

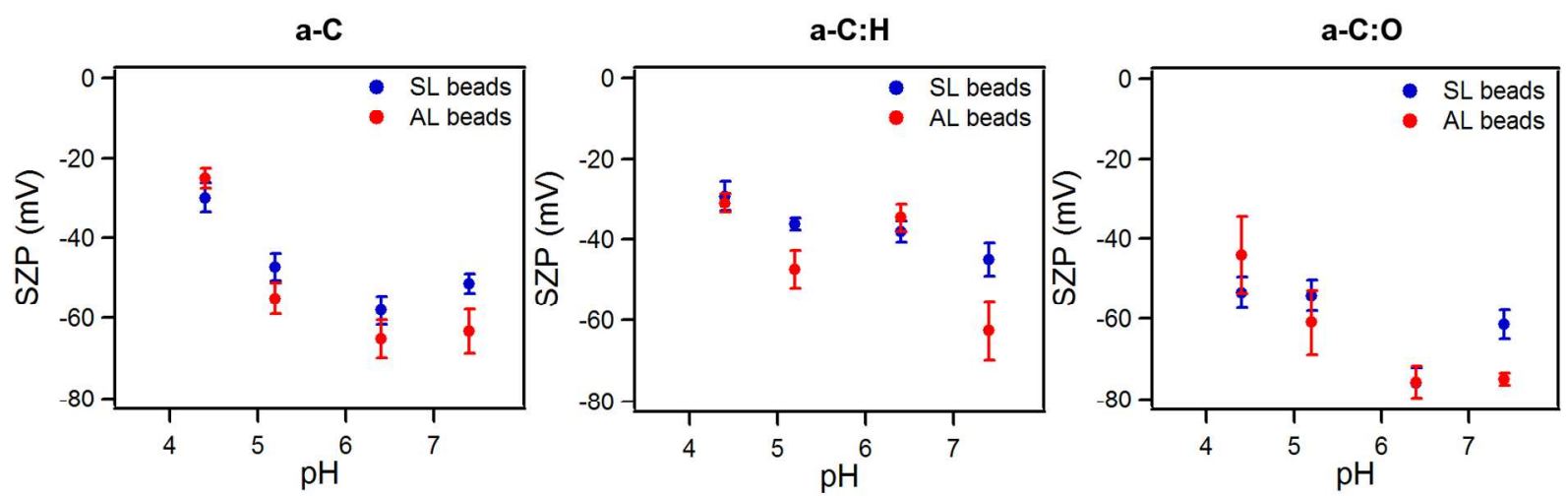

Figure 6. Surface $\zeta$-Potential of a-C, a-C:H and a-C:O surfaces obtained using SL (blue) and $\mathrm{AL}$ (red) beads as tracer particles, suspended in $100 \mu \mathrm{M}$ PBS buffer, $1.80 \pm 0.15 \mathrm{mM}$ ionic strength, for all $\mathrm{pH}$ values studied.

be $-45 \pm 4 \mathrm{mV}$ at $\mathrm{pH}$ 7.4. Finally, surface modification with UV treatment led to more negative SZP values at all pH's when compared with the pristine a-C surface; for instance, at $\mathrm{pH} 7.4$, a$\mathrm{C}: \mathrm{O}$ surfaces yielded SZP values of $-61 \pm 4 \mathrm{mV}$ and $-75 \pm 2 \mathrm{mV}$ with $\mathrm{SL}$ and $\mathrm{AL}$ beads, respectively. Even at acidic $\mathrm{pH}$, a-C:O surfaces were found to have the most negative SZP values among the three surfaces examined; an extrapolation to the $\mathrm{pH}$-axis yielded a $\mathrm{pH}_{\text {iso }}<1.5$, which is consistent with the presence of acidic groups at the surface determined via XPS.

$\mathrm{a}-\mathrm{C}$ and a-C:H were found to display negative $\mathrm{SZP}$ at all $\mathrm{pH}$ values studied, despite these carbon surfaces having a negligible amount of ionizable groups observable via XPS; moreover, in the case of a-C we were able to determine $\mathrm{pH}_{\mathrm{iso}}$ in the range 3.0-3.7. There are no available published values for SZP of sputtered a-C and a-C:H as a function of $\mathrm{pH}$ to which our results can be directly compared. However, our experimental values are in excellent agreement with published SZP determinations of other carbon surfaces with similar properties obtained using microchannel methods. Jelínek et al. ${ }^{[23]}$ studied DLC thin films and observed a similar SZP as 
that of a-C in Figure 6 and $\mathrm{pH}_{\text {iso }}=3.7$, which is identical to that obtained in this work using the tracer particle method. Nitta et al. ${ }^{[17]}$ reported negative SZP for DLC thin films independently of the degree of oxidation. Finally, Voss et al. ${ }^{[24]}$ also observed negative SZP for a diamond/a-C composite film at $\mathrm{pH}>4$, in agreement with our observations.

Negative SZP values are often ascribed to the presence of negatively charged surface groups, however, this is not the only potential mechanism of charge build-up at the solid-aqueous interface. Although it is not possible to exclude the presence of a small amount of amphoteric $\mathrm{OH}$ groups at a-C or a-C:H surfaces, these groups are not likely to give rise to negative SZP values over the $\mathrm{pH}$ range explored. The observations of (a) $\mathrm{pH}_{\mathrm{iso}}$ between 3 and 4 for a-C surfaces, (b) a relatively hydrophobic character for a-C and a-C:H surfaces and (c) the absence of a significant surface density of acidic groups, suggests that the negative SZP is instead attributable to asymmetric adsorption of hydroxide and hydronium ions at the solid-electrolyte interface. It is now well established that for hydrophobic surfaces, even in the absence of ionizable groups, the SZP in aqueous solutions is usually negative at $\mathrm{pH}>4$. This observation has a long history in the literature of electrokinetic measurements $\left(19^{\text {th }}\right.$ century $),{ }^{[42,43]}$ however it is only relatively recently that a physical model has emerged to explain this behaviour. Negative SZP at hydrophobic surfaces is attributed to the preferential adsorption of hydroxide ions at the solid surface. Hydroxide adsorption has been confirmed via simulations ${ }^{[44-46]}$ and experimental determinations, for instance at polymer surfaces, $\left.{ }^{[42,} 47\right]$ at hydrophobic self-assembled monolayers, ${ }^{[48]}$ and at diamond surfaces. ${ }^{[24,49,50]}$ In the specific case of hydrophobic carbon materials, several recent reports have confirmed hydroxide adsorption. Härtl et al. ${ }^{[50]}$ reported streaming potential measurements of $\mathrm{H}$-terminated diamond yielding a $\mathrm{pH}_{\text {iso }}$ in the range 3-4; complementary surface conductivity measurements and simulations demonstrated that this can 
be attributed to the asymmetric adsorption of $\mathrm{OH}^{-}$and $\mathrm{H}_{3} \mathrm{O}^{+}$ions. Our results on a-C and a-C:H suggest that hydroxide ion adsorption is likely to be the dominant effect, given the absence of acidic groups at theses surfaces, thus yielding negative $\mathrm{SZP}$, and $\mathrm{pH}_{\text {iso }}$ values similar to those observed at other carbon hydrophobic interfaces under similar conditions.

SZP results for a-C:O, the oxidized form of a-C, indicate that oxidation leads to more negative SZP values at all $\mathrm{pH}$ and to a decrease in isoelectric point. This is consistent with XPS results which indicate that a-C:O possesses carboxylic groups which are expected to impart greater surface acidity and increase the density of negative charges when deprotonated. Our results for a$\mathrm{C}: \mathrm{O}$ are also in good agreement with $\mathrm{SZP}$ and $\mathrm{pH}_{\text {iso }}$ values reported previously by our group and others for oxidized carbon particles. ${ }^{[18,19]}$ Moreno-Castilla et al. ${ }^{[19]}$ studied the effect of surface treatments on the SZP of carbon particles; they reported $\mathrm{pH}_{\text {iso }}$ in the range 3-4 after activation and $\mathrm{pH}_{\text {iso }}<2$ after oxidative treatments. Previous literature on SZP of carbon coatings is also in agreement with results presented in this work. Nitta et al. ${ }^{[17]}$ showed a decrease in SZP for DLC films, reporting SZP values of $-26 \mathrm{mV}$ for a-C vs. $-50 \mathrm{mV}$ for a-C:O at $\mathrm{pH}$ 5.8. Härtl et al. ${ }^{[50]}$ reported a $\mathrm{pH}_{\text {iso }}<1.5$ at $\mathrm{O}$-terminated diamond surfaces, in good agreement with the $\mathrm{pH}_{\text {iso }}$ of a$\mathrm{C}: \mathrm{O}$ surfaces presented in this work. Finally, Chakrapani et al. ${ }^{[49]}$ showed how oxidation of diamond surfaces results in $\mathrm{pH}_{\mathrm{iso}}=1$. In all cases the $\mathrm{SZP}$ trends were attributed to the dominant effect of acidic O-containing surface groups that are created via oxidative processes.

SZP values obtained with SL and AL were found to display similar trends vs. $\mathrm{pH}$ and only small differences at each of the $\mathrm{pH}$ values examined. This indicates that repulsive/attractive electrostatic interactions or acid/base interactions between the static surface and the tracer particles do not affect SZP determinations under the conditions used in our studies. Interestingly, the greatest divergence between SL and AL SZP values is observed at $\mathrm{pH}$ 7.4. This effect could 
be due to the fact that $\mathrm{AL}$ particles possess a $\zeta$-potential at $\mathrm{pH} 7.4$ at the margin of colloidal stability, thus suggesting that this is a limiting $\mathrm{pH}$ for the application of $\mathrm{AL}$ suspensions as tracers. Beyond colloidal stability, it is worth mentioning that AL beads are chemically less stable than SL beads as amine groups oxidize when exposed to air. AL beads were found to yield more negative particle SZP values than those reported in Figure 1 when measured after 30 days of storage. However, SZP determinations of carbon surfaces remained similar to those obtained with fresh AL suspensions, as long as the value chosen for the subtraction in equation (1) was the value obtained at $1000 \mu \mathrm{m}$ displacement.

\section{Conclusions}

In this work we focused on establishing, first, whether $\mathrm{pH}$-dependent surface $\zeta$-potential determinations using the tracer particle method in combination with commercially available particle suspensions are comparable to those obtained with traditional streaming potential methods. We tackled this objective by measuring $\zeta$-potential and isoelectric points of standard polymeric substrates and, indeed, found that results were comparable to reference values reported in the literature, thus confirming the applicability of the protocol.

Second, we investigated the tracer particle method for the characterization of carbon surfaces. Carbon coatings such as the ones investigated in this work, are of relevance for applications in biomaterials, diagnostics and biosensing, and $\zeta$-potential determinations are essential to understand their interactions with biomolecules, cells and organisms. Our results are the first determinations of $\mathrm{pH}$-dependent $\zeta$-potential and isoelectric points for sputtered carbon films; we present results for carbon with three different types of surface termination/chemistry: graphitic, hydrogenated and oxidized. We show that the two most hydrophobic surfaces display negative $\zeta$ - 
potential values over the range $\mathrm{pH}=4-7$; in the case of graphitic surfaces the isoelectric point could be determined to be at $\mathrm{pH}<4$. These results are consistent with the $\zeta$-potential being dominated by the asymmetric adsorption of hydroxide ions, a common finding for hydrophobic surfaces that is in agreement with prior electrokinetic results obtained on diamond materials. In the case of oxidation, we found that the presence of acidic ionizable groups leads to a significant lowering, with respect to the non-oxidized surface, of both the $\zeta$-potential and the isoelectric point.

Finally, to the best of our knowledge, there is no information currently in the literature on whether the tracer particle chemistry might affect $\zeta$-potential and isoelectric point determinations. This is an important issue in the case of carbon materials, as these can display a wide range of chemical groups and acid/base behaviour. In this work we tackled this problem by carrying out measurements using suspensions of tracer particles that possess terminal groups at the two extremes of the basicity/acidity spectrum: strong acid $\left(-\mathrm{SO}_{3} \mathrm{H}\right)$ and basic $\left(-\mathrm{NH}_{2}\right)$. Furthermore, we carried out measurements with carbon materials bearing both hydrophobic and acidic groups. Results obtained with the two types of tracer particles were found to be similar in trends and values, thus indicating that SZP determinations are not affected by the acid-base chemistry or the electrostatic interactions between the solid surface and the particle surface under our experimental conditions. However, sulfonic acid groups are more stable towards ambient oxidation than amine groups and the corresponding suspensions possess greater SZP stability over time. We believe these results to be of interest for expanding applications of the tracer particle method to other surfaces with complex chemistry.

\section{Acknowledgements}

This publication has emanated from research conducted with the financial support of Science 
Foundation Ireland under Grant No. 12/IP/1273. SNS gratefully acknowledges support by SFI Grant No. 13/CDA/2213. JAB acknowledges support from grant GOIPG/2014/399. Use of the XPS of I. V. Shvets and C. McGuinness provided under SFI Equipment Infrastructure funds. The authors are grateful to S. Mills, Dr. Esteban-Tejeda and Mr. R. Cullen for support with instrumentation.

\section{References}

[1] S. R. P. Silva, G. A. J. Amaratunga, C. P. Constantinou, J. Appl. Phys. 1992, 72, 1149.

[2] J. Robertson, Surf. Coat. Technol. 1992, 50, 185.

[3] A. S. Barnard, The Analyst 2009, 134, 1751.

[4] O. Faklaris, V. Joshi, T. Irinopoulou, P. Tauc, M. Sennour, H. Girard, C. Gesset, J. C. Arnault, A. Thorel, J. P. Boudou, P. A. Curmi, F. Treussart, ACS Nano 2009, 3, 3955.

[5] F. Liang, B. Chen, Curr. Med. Chem. 2010, 17, 10.

[6] S. K. Bhunia, A. Saha, A. R. Maity, S. C. Ray, N. R. Jana, Sci. Rep. 2013, 3, 1473.

[7] Y.-P. Sun, B. Zhou, Y. Lin, W. Wang, K. A. S. Fernando, P. Pathak, M. J. Meziani, B. A. Harruff, X. Wang, H. Wang, P. G. Luo, H. Yang, M. E. Kose, B. Chen, L. M. Veca, S.-Y. Xie, J. Am. Chem. Soc. 2006, 128, 7756.

[8] A. K. Geim, K. S. Novoselov, Nat. Mater. 2007, 6, 183.

[9] M. F. L. De Volder, S. H. Tawfick, R. H. Baughman, A. J. Hart, Science 2013, 339, 535.

[10] R. K. Roy, K. R. Lee, J. Biomed. Mater. Res., Part B 2007, 83, 72.

[11] M. Stüber, L. Niederberger, F. Danneil, H. Leiste, S. Ulrich, A. Welle, M. Marin, H. Fischer, Adv. Eng. Mater. 2007, 9, 1114.

[12] L. An, Q. Fu, C. Lu, J. Liu, J. Am. Chem. Soc. 2004, 126, 10520.

[13] K. Balasubramanian, R. Sordan, M. Burghard, K. Kern, Nano Lett. 2004, 4, 827.

[14] J. Robertson, Mater. Sci. Eng., R 2002, 37, 129.

[15] C. Werner, H. Körber, R. Zimmermann, S. Dukhin, H.-J. Jacobasch, J. Colloid Interface Sci. 1998, 208, 329.

[16] C. Werner, H. J. Jacobasch, Int. J. Artif. Organs 1999, 22, 160. 
[17] Y. Nitta, K. Okamoto, T. Nakatani, H. Hoshi, A. Homma, E. Tatsumi, Y. Taenaka, Diamond Relat. Mater. 2008, 17, 1972.

[18] P. Duffy, L. M. Magno, R. B. Yadav, S. K. Roberts, A. D. Ward, S. W. Botchway, P. E. Colavita, S. J. Quinn, J. Mater. Chem. 2012, 22, 432.

[19] C. Moreno-Castilla, M. A. Ferro-Garcia, J. P. Joly, I. Bautista-Toledo, F. CarrascoMarin, J. Rivera-Utrilla, Langmuir 1995, 11, 4386.

[20] A. V. Delgado, F. Gonzalez-Caballero, R. J. Hunter, L. K. Koopal, J. Lyklema, P. International Union of, P. Applied Chemistry, I. T. R. Biophysical Chemistry Division, $J$. Colloid Interface Sci. 2007, 309, 194.

[21] B. J. Kirby, E. F. Hasselbrink, Jr., Electrophoresis 2004, 25, 203.

[22] T. Nakatani, Y. Nitta, K. Okamoto, A. Mochizuki, J. Photopolym. Sci. Technol. 2009, 22, 455.

[23] M. Jelínek, K. Smetana, T. Kocourek, B. Dvořánková, J. Zemek, J. Remsa, T. Luxbacher, Materials Science and Engineering: B 2010, 169, 89.

[24] A. Voss, H. Wei, C. Müller, C. Popov, W. Kulisch, G. Ceccone, C. Ziegler, M. Stengl, J. P. Reithmaier, Diamond Relat. Mater. 2012, 26, 60.

[25] D. Yan, C. Yang, N. T. Nguyen, X. Huang, Electrophoresis 2006, 27, 620.

[26] J. C. W. Corbett, F. McNeil-Watson, R. O. Jack, M. Howarth, Colloids Surf., A 2012 , $396,169$.

[27] J. Corbett, F. Mcneil-Watson, R. Jack, Surface charge measurement, Patent No. WO2012172330 A1, 2012.

[28] I. M. Tucker, J. C. W. Corbett, J. Fatkin, R. O. Jack, M. Kaszuba, B. MacCreath, F. McNeil-Watson, Curr. Opin. Colloid Interface Sci. 2015, 20, 215.

[29] R. J. Cullen, D. R. Jayasundara, L. Soldi, J. J. Cheng, G. Dufaure, P. E. Colavita, Chem. Mater. 2012, 24, 1031.

[30] J. M. Simmons, B. M. Nichols, S. E. Baker, M. S. Marcus, O. M. Castellini, C. S. Lee, R. J. Hamers, M. A. Eriksson, J. Phys. Chem. B 2006, 110, 7113.

[31] P. E. Colavita, B. Sun, X. Wang, R. J. Hamers, J. Phys. Chem. C 2009, 113, 1526.

[32] F. Zen, M. D. Angione, J. A. Behan, R. J. Cullen, T. Duff, J. M. Vasconcelos, E. M. Scanlan, P. E. Colavita, Sci. Rep. 2016, 24840.

[33] M. R. Gittings, D. A. Saville, Colloids Surf., A 1998, 141, 111.

[34] F. Thielbeer, K. Donaldson, M. Bradley, Bioconjugate Chem. 2011, 22, 144. 
[35] F. Ganachaud, A. Elaïssari, C. Pichot, A. Laayoun, P. Cros, Langmuir 1997, 13, 701.

[36] H. M. Rendall, A. L. Smith, J. Chem. Soc., Faraday Trans. 1978, 1179.

[37] X. L. Peng, Z. H. Barber, T. W. Clyne, Surf. Coat. Technol. 2001, 138, 23.

[38] G. Dearnaley, J. H. Arps, Surf. Coat. Technol. 2005, 200, 2518.

[39] E. Johansson, L. Nyborg, Surf. Interface Anal. 2003, 35, 375.

[40] P. B. Leezenberg, W. H. Johnston, G. W. Tyndall, J. Appl. Phys. 2001, 89, 3498.

[41] A. Zebda, H. Sabbah, S. Ababou-Girard, F. Solal, C. Godet, Appl. Surf. Sci. 2008, 254, 4980.

[42] J. K. Beattie, Lab Chip 2006, 6, 1409.

[43] L. S. McCarty, G. M. Whitesides, Angew. Chem., Int. Ed. Engl. 2008, 47, 2188.

[44] H. J. Kreuzer, R. L. C. Wang, M. Grunze, J. Am. Chem. Soc. 2003, 125, 8384.

[45] K. N. Kudin, R. Car, J. Am. Chem. Soc. 2008, 130, 3915.

[46] R. Zangi, J. B. F. N. Engberts, J. Am. Chem. Soc. 2005, 127, 2272.

[47] R. Zimmermann, S. Dukhin, C. Werner, J. Phys. Chem. B 2001, 105, 8544.

[48] C. Dicke, G. Hähner, J. Am. Chem. Soc. 2002, 124, 12619.

[49] V. Chakrapani, J. C. Angus, A. B. Anderson, S. D. Wolter, B. R. Stoner, G. U. Sumanasekera, Science 2007, 318, 1424.

[50] A. Hartl, J. A. Garrido, S. Nowy, R. Zimmermann, C. Werner, D. Horinek, R. Netz, M. Stutzmann, J. Am. Chem. Soc. 2007, 129, 1287. 

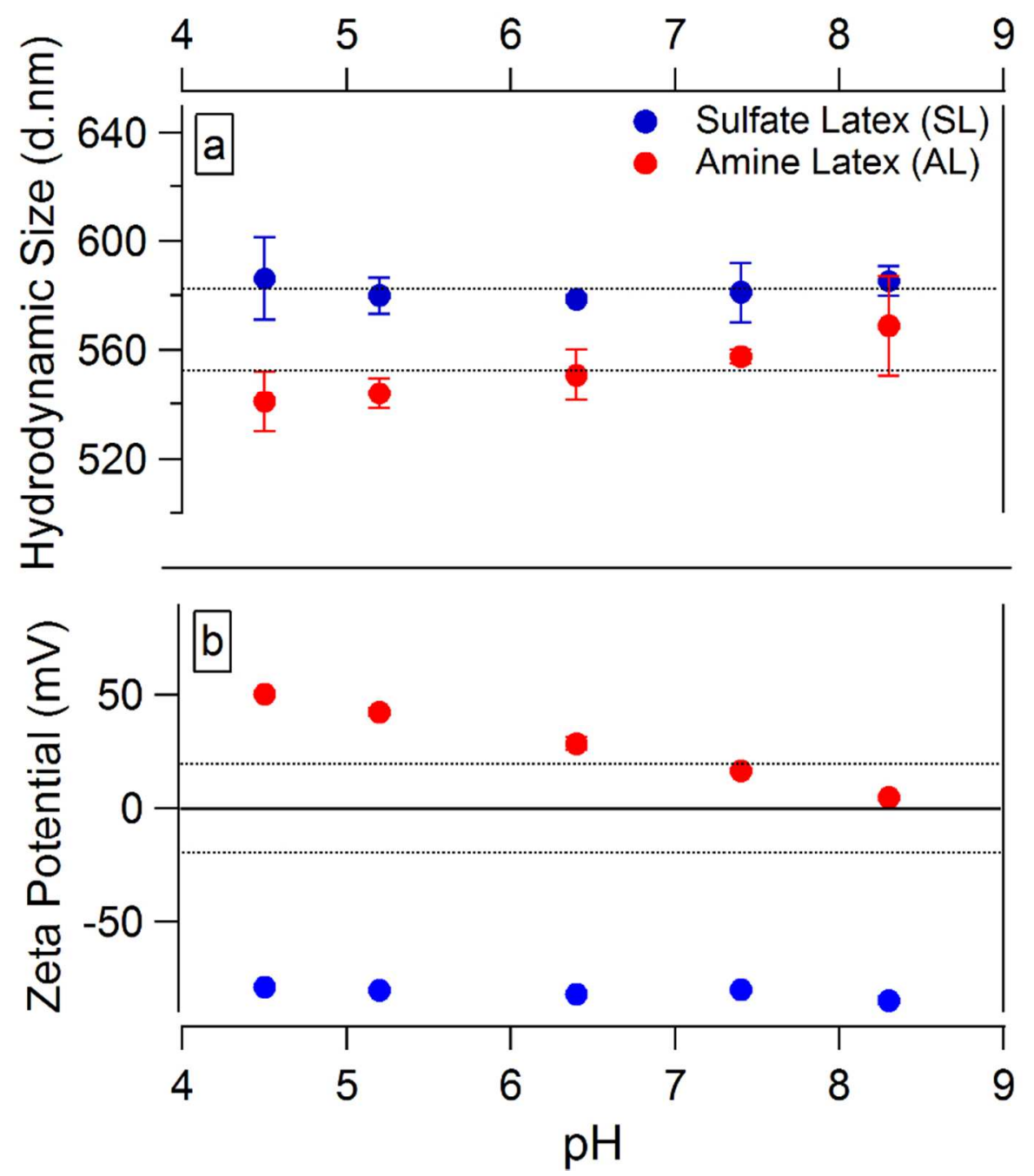

Figure 1. (a) Hydrodynamic size and (b) $\zeta$-potential of sulfate latex (SL) and amine latex (AL) beads used as tracer particles for surface $\zeta$-potential measurements. SL and AL beads were suspended in $100 \mu \mathrm{M}$ PBS buffer $(1.37 \mathrm{mM} \mathrm{NaCl}$ and $27 \mu \mathrm{M} \mathrm{KCl})$ with total ionic strength of $1.80 \pm 0.15 \mathrm{mM}$ for all $\mathrm{pH}$ values studied. Figure 1

$82 \times 89 \mathrm{~mm}(300 \times 300 \mathrm{DPI})$ 
1

2

3

4

5

6

7

8

9

10

11

12

13

14

15

16

17

18

19

20

21

22

23

24

25

26

27

28

29

30

31

32

33

34

35

36

37

38

39

40

41

42

43

44

45

46

47

48

49

50

51

52

53

54

55

56

57

58

59

60

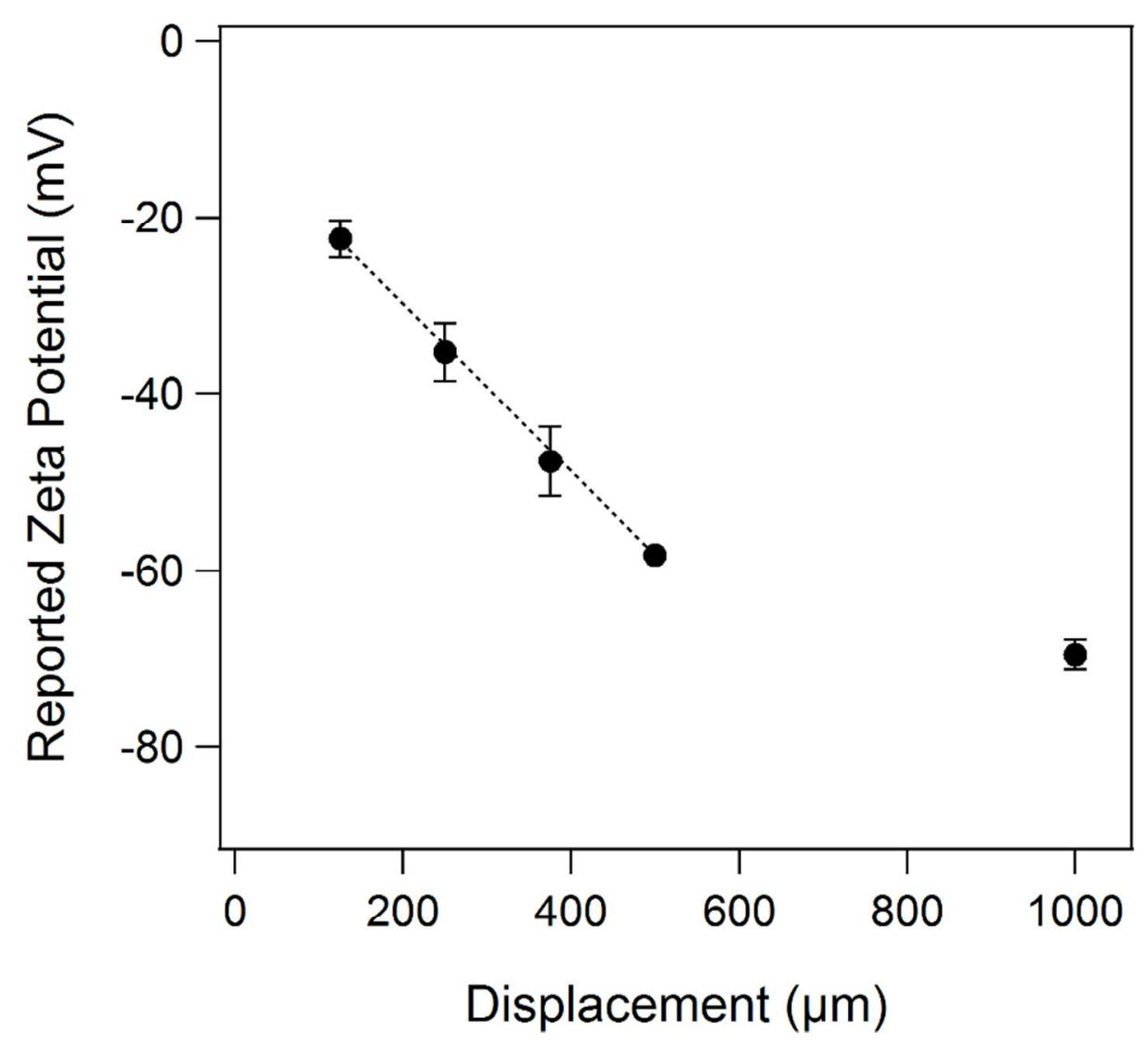

Figure 2. Plot of apparent $\zeta$-potential as a function of surface displacement obtained for Nylon 6,6 as a static surface using SL beads in $100 \mu \mathrm{M}$ PBS buffer ( $\mathrm{pH}$ 7.5) as tracer particles.

Figure 2

$85 \times 73 \mathrm{~mm}(300 \times 300 \mathrm{DPI})$ 


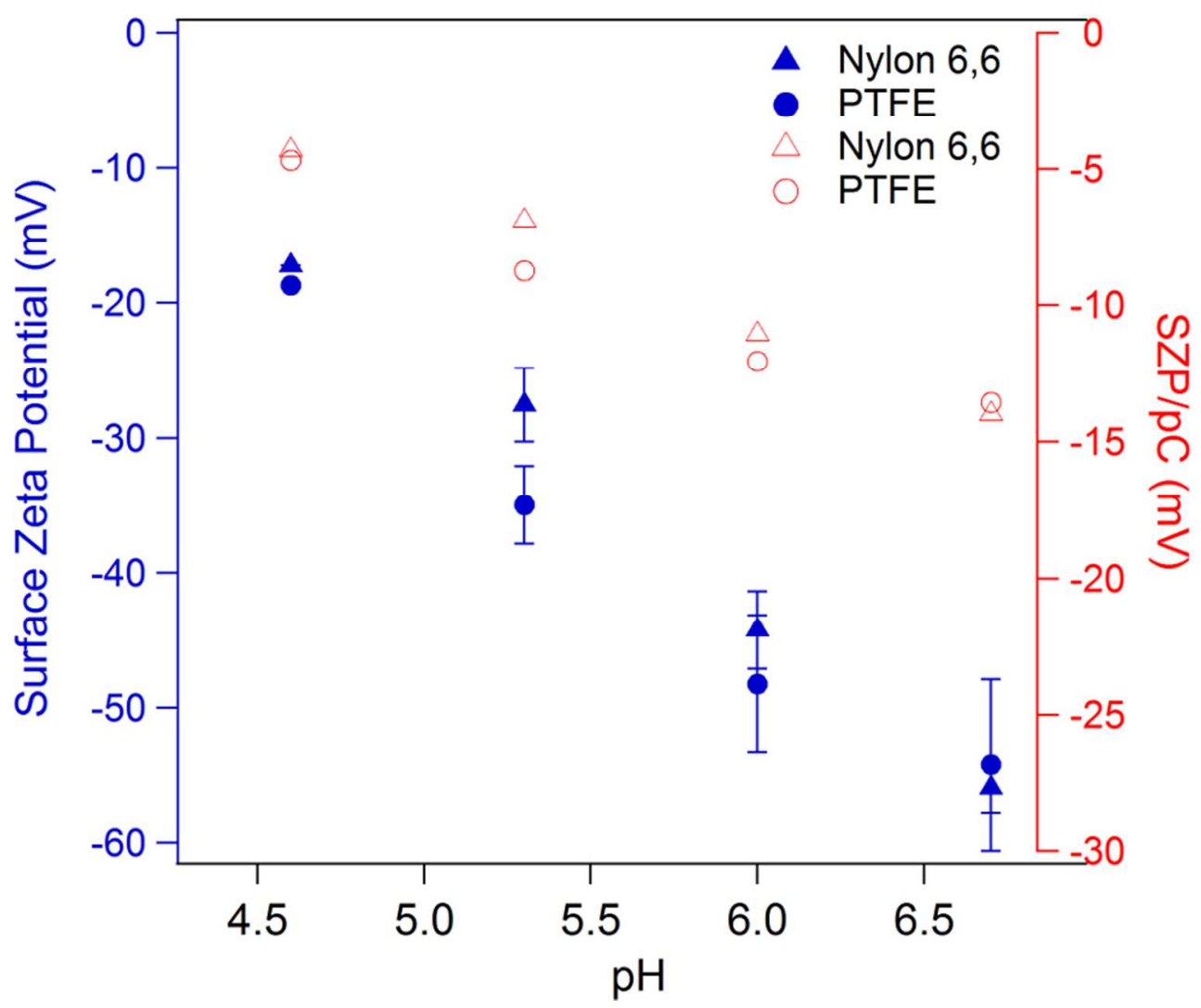

Figure 3. Surface $\zeta$-potential measurements of Nylon 6,6 and PTFE surfaces (blue data points) using SL beads as tracer particles. SL beads were suspended in $100 \mu \mathrm{M}$ PBS buffer $(1.37 \mathrm{mM} \mathrm{NaCl}$ and $27 \mu \mathrm{M} \mathrm{KCl})$ and the ionic strength remained at $1.80 \pm 0.15 \mathrm{mM}$ for all $\mathrm{pH}$ studied $(\mathrm{pC}=2.82)$. Surface $\zeta$-potential values were normalized by the counterion concentration $(\mathrm{pC})$ for both polymers (red data points).

Figure 3

$85 \times 71 \mathrm{~mm}(300 \times 300$ DPI $)$ 


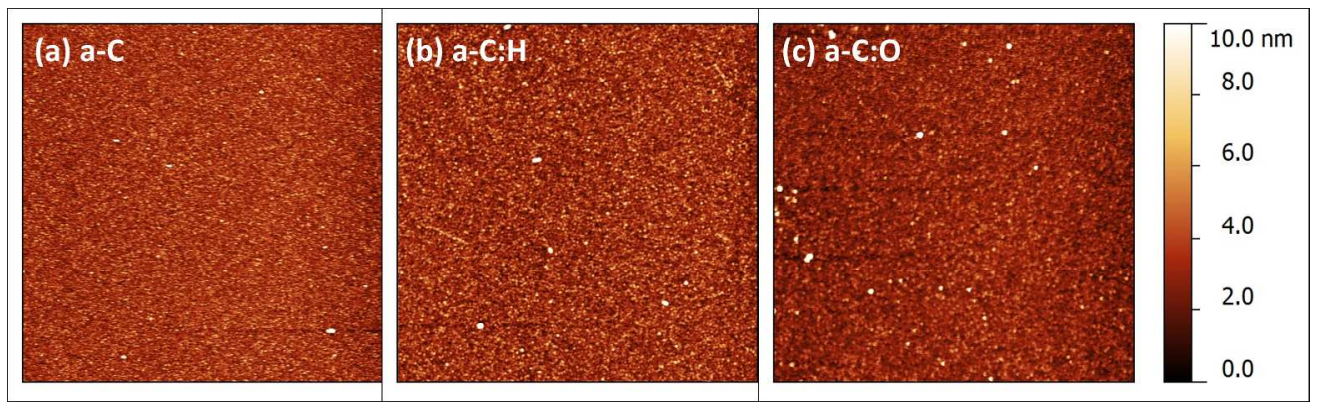

Figure 4. $10 \times 10 \mu \mathrm{m}$ AFM topographic images of (a) a-C, (b) a-C:H and (c) a-C:O surfaces. Surfaces roughness values were obtained from height profile determinations.

Figure 4 
لسسلسلسلسلسلسلسلسلسلسلسلسلسل 282

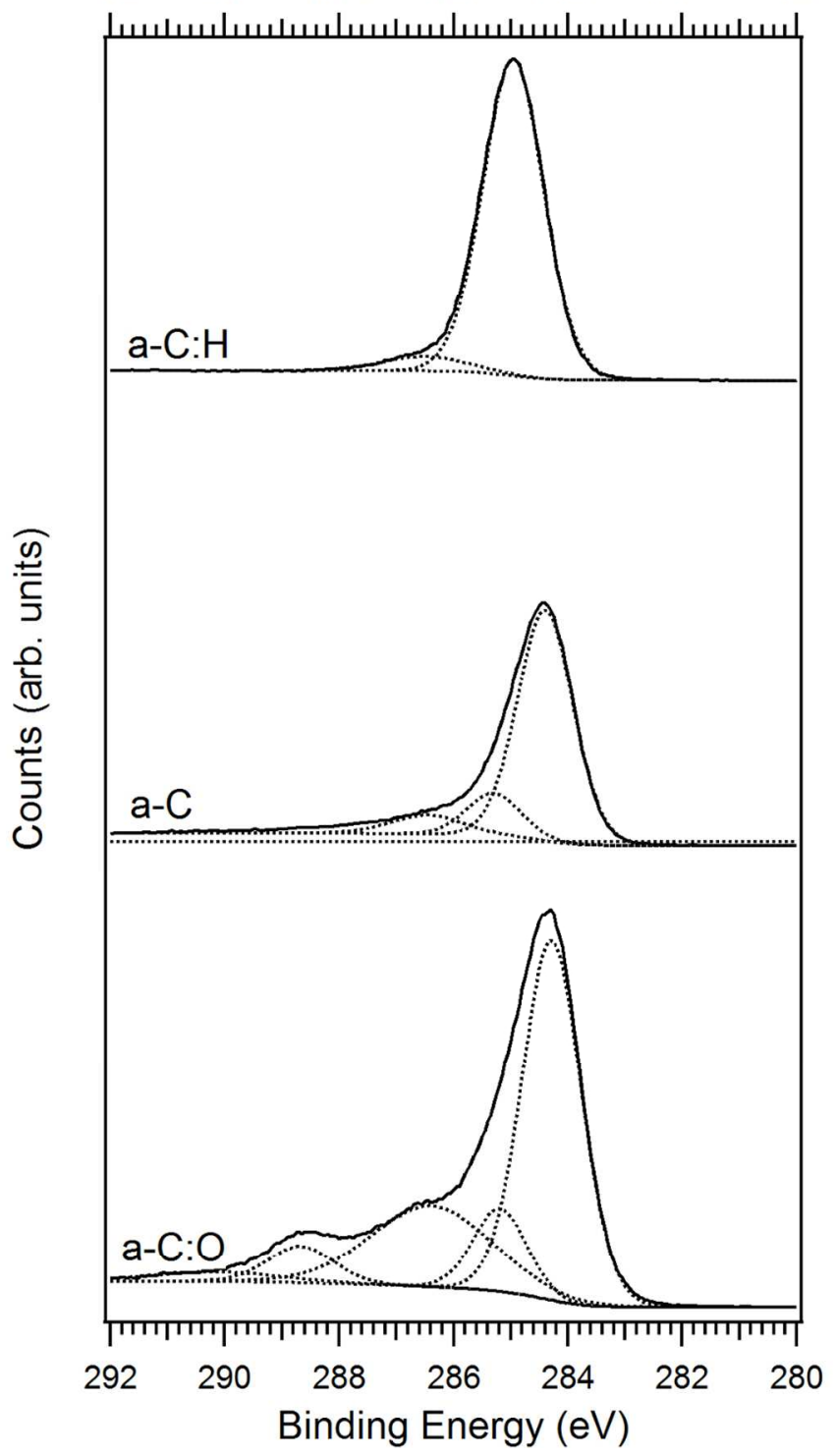

Figure 5. XPS spectra of a-C:H, a-C and a-C:O in the $\mathrm{C} 1 \mathrm{~s}$ region; Shirley background and individual contributions are shown under each curve. Figure 5 $85 \times 148 m m(300 \times 300$ DPI $)$ 

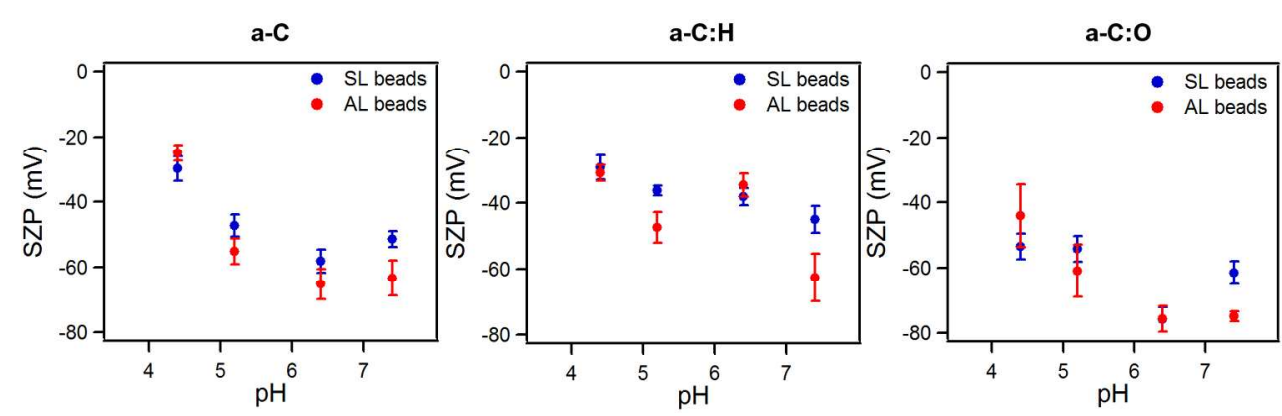

Figure 6. Surface $\zeta$-Potential of a-C, a-C:H and a-C:O surfaces obtained using $\mathrm{SL}$ (blue) and $\mathrm{AL}$ (red) beads as tracer particles, suspended in $100 \mu \mathrm{M}$ PBS buffer, $1.80 \pm 0.15 \mathrm{mM}$ ionic strength, for all $\mathrm{pH}$ values studied.

Figure 6

$180 \times 54 \mathrm{~mm}(300 \times 300 \mathrm{DPI})$ 